\title{
Clinical and Immunological Effects of p53-Targeting Vaccines
}

\author{
Shan Zhou ${ }^{1}$, Chunmei Fan ${ }^{1,2}$, Zhaoyang Zeng ${ }^{2}$, Ken H. Young ${ }^{3}$ and Yong $\mathrm{Li}^{1,2 *}$ \\ ${ }^{1}$ Section of Epidemiology and Population Science, Department of Medicine, Baylor College of Medicine, Houston, TX, \\ United States, ${ }^{2}$ The Key Laboratory of Carcinogenesis and Cancer Invasion of the Chinese Ministry of Education, Cancer \\ Research Institute and School of Basic Medicine, Central South University, Changsha, China, ${ }^{3}$ Hematopathology Division, \\ Department of Pathology, Duke University Medical Center, Durham, NC, United States
}

Immunotherapy, including immune checkpoint blockade and chimeric antigen receptor $T$ cells, is one of the most promising approaches to treat cancer. Vaccines have been effective in preventing cancers like liver cancer and cervical cancer with a viral etiology. Instead of preventing disease, therapeutic cancer vaccines mobilize the immune system to attack existing cancer. p53 is dysregulated in the majority of human cancers and is a highly promising target for cancer vaccines. Over twenty clinical trials have targeted p53 in malignant diseases using vaccines. In this work, we review the progress of vaccinations with p53 or its peptides as the antigens and summarize the clinical and immunological effects of p53-targeting vaccines from clinical trials. The delivery platforms include p53 peptides, viral vectors, and dendritic cells pulsed with short peptides or transduced by p53-encoding viruses. These studies shed light on the feasibility, safety, and clinical benefit of p53 vaccination in select groups of patients, implicating that p53-targeting vaccines warrant further investigations in experimental animals and human studies.

Keywords: p53, vaccine, Cancer, immunotherapy, $\mathrm{T}$ cell

\section{INTRODUCTION}

TP53 gene encodes the transcription factor p53, one of the most important tumor suppressors. Under physiological conditions, p53 expression is tightly controlled and maintains a low level due to rapid degradation by the ubiquitin-mediated proteolysis. The E3 ubiquitin ligase MDM2 and its structural homolog MDMX (also known as MDM4) are the best known negative regulators of p53 (Manfredi, 2021). MDM2 polyubiquitylates p53 and results in proteasome-mediated degradation and monoubiquitylates p53 lead to export p53 out of the nucleus (Wu and Prives, 2018). Furthermore, MDM2 direct interacts with p53 to disrupt the transcriptional activity (Wu and Prives, 2018). Finally, MDM2 is a p53 target gene, thus creating an auto-regulatory feedback loop. MDMX has no ubiquitylation activity, but it binds p53 and inactivates it directly or heterodimerizes with MDM2 to aid MDM2 in p53 ubiquitylation (Wade et al., 2010; Karni-Schmidt et al., 2016; Yang et al., 2021). Under cellular stress, p53 becomes activated and stabilized to transcriptionally regulate target genes that are pivotal to various cellular processes, including cell cycle arrest, apoptosis, and DNA repair (Janic et al., 2018; Boutelle and Attardi, 2021).

Received: 22 August 2021 Accepted: 18 October 2021 Published: 03 November 2021

Citation:

Zhou S, Fan C, Zeng Z, Young KH and Li Y (2021) Clinical and Immunological Effects of p53-Targeting Vaccines. Front. Cell Dev. Biol. 9:762796. doi: 10.3389/fcell.2021.762796

\section{P53 IN CANCER}

Germline or somatic mutation in the TP53 gene is frequently found in human cancers (Malkin et al., 1990; Hollstein et al., 1991). Missense mutations are the most common mutation type in cancer tissues, leading to mutant p53 accumulation in tumor cells (Petitjean et al., 2007; Mantovani et al., 
2019). Mutations occur throughout the p53 protein but predominantly are located at exons 4-9 that encode the DNA binding domain, including six "hotspot" residues, namely R175, G245, R248, R249, R273, and R282 (Leroy et al., 2014; Bouaoun et al., 2016). Missense TP53 mutations are classified as contact or structural mutations. Contact mutations, such as R248Q, R273H, and $\mathrm{R} 273 \mathrm{C}$, disrupt $\mathrm{p} 53$ DNA binding, resulting in loss of essential protein-DNA contacts. Structural mutations, such as R175H, G245S, Y220C, and R249S, destabilize the p53 structure and reduce its thermostability (Joerger and Fersht, 2007). Most p53 mutants not only lose wild-type (WT) p53 activity (i.e., loss of function $[\mathrm{LOF}]$ ) but also obtain dominant-negative (DN) functions to antagonize the remaining WT p53 (Nakayama et al., 2020; Tang et al., 2020). Furthermore, many p53 mutants acquire gain of function (GOF) activity (Nakayama et al., 2020; Tang et al., 2020), though this is debated (Boettcher et al., 2019). Thus, mutant TP53 acts as an oncogene that promotes tumor cells' survival, proliferation, invasion, and metastasis. However, the TP53 mutation rates differ significantly in anatomical tumor sites (Wang and Sun, 2017). A Pan-Cancer cohort showed TP53 was the most frequently mutated gene ( $42 \%$ of samples); it is mutated in 95\% serous ovarian cancer, but only in $2.2 \%$ renal clear cell carcinoma (Kandoth et al., 2013). The incidence of the LOF p53 mutations is associated with increased chemotherapy resistance and lower efficacy of anti-tumor agents (Keshelava et al., 2001). Overexpress WT p53 in tumor cells increase p53 protein level and lead to cell growth arrest or apoptosis (Ramqvist et al., 1993; McIlwrath et al., 1994). Furthermore, mouse models have demonstrated that the significance of p53 as a regulator of tumor suppression and therapy in vivo (Iwakuma and Lozano, 2007). p53 upregulates the expression of CDKN1A, BAX, PUMA, and NOXA, resulting in cell-cycle arrest, apoptosis, and senescence in vivo (Brady et al., 2011; Li et al., 2012).

p53 also plays a pivotal role in regulating inflammation in cancer through its activities in non-cancer cells. Lowe and colleagues showed that in the presence of chronic liver damage, ablation of a p53-dependent senescence program in hepatic stellate cells enhanced the transformation of adjacent epithelial cells into hepatocellular carcinoma by skewing macrophage polarization towards a tumor-promoting M2-state (Lujambio et al., 2013). Mice with a targeted deletion of p53 in myeloid cells selectively lost the $\mathrm{Ly} 6 \mathrm{c}^{+} \mathrm{CD} 103^{+}$population and became unresponsive to immunotherapy and immunogenic chemotherapy, supporting that p53 drives differentiation of monocytic precursor cells into dendritic cells and macrophages for cross-presentation of tumor antigens (Sharma et al., 2018). MDM2 promoted $\mathrm{T}$ cell-mediated anti-tumor immunity by preventing c-Cbl-mediated STAT5 degradation; targeting the p53-MDM2 interaction with a pharmacological agent (APG115) augmented MDM 2 in $\mathrm{T}$ cells, boosted $\mathrm{T}$ cell immunity, and synergized with cancer immunotherapy (Zhou et al., 2021).

Multiple p53-targeting therapeutic strategies have been attempted. For tumors with WT p53, the approach is to suppress the interaction between $\mathrm{p} 53$ and MDM2/MDMX, inhibit the degradation of WT p53, and maintain the needed levels of p53 in cells, thus promote tumor suppression. For tumors with mutant $\mathrm{p} 53$, therapeutic agents are developed to reactivate mutant p53 or promote its degradation (Chen et al., 2021). Targeting the p53 signaling pathway has been extensively reviewed by a number of investigators (Hernández Borrero and El-Deiry, 2021; Huang, 2021; Liu et al., 2021; Salomao et al., 2021). At least theoretically, therapeutic restoration of inactivated tumor suppressors is more challenging than inhibiting an oncogenic target. Indeed, no therapy has successfully reactivated a mutated tumor suppressor in a clinical setting. Furthermore, p53 is an intracellular protein, making it inaccessible to antibodies.

\section{CANCER IMMUNOTHERAPY}

Cancer immunotherapy manipulates the immune system to recognize and destroy cancer cells. Therapeutic cancer vaccines are an exciting development in cancer immunotherapy by eliciting specific immune responses to tumor antigens. $\mathrm{CD}^{+}$cytotoxic $\mathrm{T}$ lymphocytes (CTLs) are preferred effector cells for anti-tumor immune responses (Hossain et al., 2021). CD8 ${ }^{+}$CTLs act as the key player in mediating tumor suppression through recognition of tumorspecific or associated antigens. $\mathrm{T}$ lymphocytes recognize antigens presented by antigen-presenting cells (APCs) in a major histocompatibility-restricted manner. Dendritic cells (DCs), discovered and characterized by Steinman and Cohn in 1973, are the most efficient APCs (Steinman and Cohn, 1973; Steinman and Cohn, 1974; Steinman et al., 1975). DCs participate in a variety of immunological processes, including initiating immune responses and sustaining effective T-cell-mediated anti-tumor immune responses (Marciscano and Anandasabapathy, 2021). DCs are classified into immature and mature according to their developmental stage. When immature DCs recognize, uptake, and cross-present the antigens released by tumor cells, they shift to secondary lymphoid organs, where they activate $\mathrm{CD}^{+} \mathrm{T}$ cells or $\mathrm{CD}{ }^{+} \mathrm{T}$ cells to trigger specific CTLs responses against target cells (Wang et al., 2020a).

\section{VACCINES TARGETING P53}

Both WT and mutant p53 epitopes can be presented on the cell surface in the context of MHC I molecules by APCs for CD8 ${ }^{+}$ $\mathrm{T}$ cell recognition (Houbiers et al., 1993). CTLs recognizing the WT p53 $3_{25-35}, \mathrm{p} 53_{110-124}, \mathrm{p} 53_{108-122}, \mathrm{p} 53_{149-157}$, and p53 $264-272$ epitopes have been reported, and many are used for developing potentially broadly applicable cancer vaccines (Chikamatsu et al., 1999; Chikamatsu et al., 2003; Rojas et al., 2005; Ito et al., 2006). p53110-124 specific $\mathrm{CD}^{+} \mathrm{T}$ cells promote the generation and function of tumor-specific CD8 ${ }^{+}$CTLs (Chikamatsu et al., 2003). Short peptides from a mouse mutant $\mathrm{p} 53$ are recognized by $\mathrm{CD} 4^{+}$ and $\mathrm{CD}^{+} \mathrm{T}$ cells, and vaccination with a mutant peptide emulsified in incomplete Freund's adjuvant leads to tumor inhibition (Noguchi et al., 1994; Theobald et al., 1995). p53 mutations are associated with overexpression of mutant p53 in cancer cells, which may lead to the abnormal presentation of p53 
TABLE 1 | Clinical trials with p53-targeting vaccines in human Cancers.

\begin{tabular}{|c|c|c|c|c|c|c|c|c|c|}
\hline Author & Year & Phase & $\begin{array}{l}\text { Vaccine } \\
\text { platform }\end{array}$ & Antigen $^{\mathrm{a}, \mathrm{b}}$ & Disease & $\begin{array}{c}\text { Patient } \\
\text { no }\end{array}$ & $\begin{array}{l}\text { Disease } \\
\text { state }\end{array}$ & $\begin{array}{l}\text { Previous } \\
\text { treatment }\end{array}$ & $\begin{array}{c}\text { Immunizations } \\
\text { (x) }\end{array}$ \\
\hline Kuball & 2002 & $\begin{array}{l}\text { Pilot } \\
\text { study }\end{array}$ & $\begin{array}{l}\text { Recombinant } \\
\text { adenovirus }\end{array}$ & WT FL p53 & $\begin{array}{l}\text { Urogenital, lung cancer, } \\
\text { malignant schwannoma }\end{array}$ & 6 & $\begin{array}{l}\text { Advanced } \\
\text { disease }\end{array}$ & Unknown & 4 \\
\hline Menon & 2003 & $1 / I I$ & $\begin{array}{l}\text { Recombinant } \\
\text { canarypox virus }\end{array}$ & WT FL p53 & Colorectal cancer & 16 & $\begin{array}{l}\text { Metastatic } \\
\text { disease }\end{array}$ & $\begin{array}{l}\text { Chemotherapy/ } \\
\text { radiation } \\
\text { therapy/other }\end{array}$ & 3 \\
\hline Svane & 2004 & I & $\begin{array}{l}\text { Short peptide- } \\
\text { pulsed DC }\end{array}$ & WT p53 peptide & HLA-A2 ${ }^{+}$breast cancer & 6 & $\begin{array}{l}\text { Metastatic } \\
\text { disease }\end{array}$ & $\begin{array}{l}\text { Chemotherapy/ } \\
\text { radiotherapy/ } \\
\text { endocrine }\end{array}$ & 10 \\
\hline Lomas & 2004 & 1 & $\begin{array}{l}\text { Short peptides } \\
\text { plus GM-CSF }\end{array}$ & $\begin{array}{l}\text { Short peptides } \\
\text { derived from } \\
\text { human anti-p53 } \\
\text { (WT denatured) } \\
\text { antibodies }\end{array}$ & $\begin{array}{l}\text { Breast, colorectal, non- } \\
\text { small-cell lung, renal, } \\
\text { prostate, head- and neck, } \\
\text { hemangiopericytoma, } \\
\text { esophageal cancer }\end{array}$ & 14 & $\begin{array}{l}\text { NED/metastatic } \\
\text { /recurrent } \\
\text { disease }\end{array}$ & Yes & 4 \\
\hline Antonia & 2006 & $|/| \mid$ & $\begin{array}{l}\text { Recombinant } \\
\text { adenovirus- } \\
\text { transduced DC }\end{array}$ & WT FL p53 & Small cell lung cancer & 29 & $\begin{array}{l}\text { Extensive/ } \\
\text { recurrent disease }\end{array}$ & Chemotherapy & 3 or 6 \\
\hline Svane & 2007 & $\|$ & $\begin{array}{l}\text { Short peptide- } \\
\text { pulsed DC }\end{array}$ & $\begin{array}{l}3 \text { WT p53 } \\
\text { peptides }+3 \\
\text { mutant p53 } \\
\text { peptides (to } \\
\text { enhance HLA- } \\
\text { A2 binding }\end{array}$ & HLA-A2 ${ }^{+}$breast cancer & 26 & Metastatic & $\begin{array}{l}\text { Regimens/ } \\
\text { endocrine }\end{array}$ & 10 \\
\hline Leffers & 2009 & $\|$ & Long peptide & $\begin{array}{l}10 \text { long } \\
\text { peptides } \\
\text { covering WT } \\
\text { p53 (70-248) }\end{array}$ & Ovarian cancer & 20 & $\begin{array}{l}\text { Recurrent } \\
\text { disease }\end{array}$ & $\begin{array}{l}\text { Surgery/ } \\
\text { chemotherapy }\end{array}$ & 4 \\
\hline Speetjens & 2009 & $|/| \mid$ & Long peptide & $\begin{array}{l}10 \text { long } \\
\text { peptides } \\
\text { covering WT } \\
\text { p53 (70-248) }\end{array}$ & Colorectal cancer & 10 & $\begin{array}{l}\text { Metastatic } \\
\text { disease }\end{array}$ & $\begin{array}{l}\text { Surgery/ } \\
\text { chemotherapy }\end{array}$ & 2 \\
\hline Rahma & 2012 & $\|$ & $\begin{array}{l}\text { Short peptide } \\
\text { pulsed-DC }\end{array}$ & $\begin{array}{l}\text { Short WT p53 } \\
\text { peptide }\end{array}$ & HLA-A2 ${ }^{+}$ovarian cancer & 21 & $\begin{array}{l}\text { Advanced/ } \\
\text { recurrent disease }\end{array}$ & Yes & 4 \\
\hline Vermeij & 2012 & $\|$ & Long peptide & $\begin{array}{l}10 \text { long } \\
\text { peptides } \\
\text { covering WT } \\
\text { p53 (70-248) }\end{array}$ & Ovarian cancer & 12 & $\begin{array}{l}\text { Recurrent } \\
\text { disease }\end{array}$ & Chemotherapy & 4 \\
\hline Iclozan & 2013 & $\|$ & $\begin{array}{l}\text { Recombinant } \\
\text { adenovirus- } \\
\text { transduced DC }\end{array}$ & WT FL p53 & Small cell lung cancer & 56 & $\begin{array}{l}\text { Advanced } \\
\text { disease }\end{array}$ & $\begin{array}{l}\text { Chemotherapy/ } \\
\text { radiotherapy }\end{array}$ & 3 \\
\hline Zeestraten & 2013 & $|/| \mid$ & $\begin{array}{l}\text { Long peptide } \\
\text { plus IFN- } \alpha\end{array}$ & $\begin{array}{l}10 \text { long } \\
\text { peptides } \\
\text { covering WT } \\
\text { p53 (70-248) }\end{array}$ & Colorectal cancer & 11 & $\begin{array}{l}\text { Metastatic } \\
\text { disease }\end{array}$ & $\begin{array}{l}\text { Surgery/ } \\
\text { chemotherapy/ } \\
\text { radiotherapy }\end{array}$ & 2 \\
\hline Hardwick & 2014 & I & $\begin{array}{l}\text { Recombinant } \\
\text { vaccinia Ankara } \\
\text { virus }\end{array}$ & WT FL p53 & $\begin{array}{l}\text { Pancreatic cancer, colon } \\
\text { cancer }\end{array}$ & 12 & $\begin{array}{l}\text { Unresectable } \\
\text { and } \\
\text { chemotherapy- } \\
\text { resistant disease }\end{array}$ & $\begin{array}{l}\text { Chemotherapy/ } \\
\text { radiotherapy }\end{array}$ & 3 \\
\hline Schuler & 2014 & । & $\begin{array}{l}\text { Short peptide- } \\
\text { pulsed DC }\end{array}$ & $\begin{array}{l}\text { Short WT p53 } \\
\text { peptides } \\
\text { (mutated to }\end{array}$ & $\mathrm{HLA}-\mathrm{A}^{+}{ }^{+} \mathrm{HNSCC}$ & 16 & $\begin{array}{l}\text { Advanced } \\
\text { disease }\end{array}$ & $\begin{array}{l}\text { Surgery/ } \\
\text { chemotherapy }\end{array}$ & 3 \\
\hline
\end{tabular}


TABLE 1 | (Continued) Clinical trials with p53-targeting vaccines in human Cancers.

\begin{tabular}{|c|c|c|c|c|c|c|c|c|c|}
\hline Author & Year & Phase & $\begin{array}{l}\text { Vaccine } \\
\text { platform }\end{array}$ & Antigen $^{\mathrm{a}, \mathrm{b}}$ & Disease & $\begin{array}{l}\text { Patient } \\
\text { no }\end{array}$ & $\begin{array}{l}\text { Disease } \\
\text { state }\end{array}$ & $\begin{array}{l}\text { Previous } \\
\text { treatment }\end{array}$ & $\begin{array}{c}\text { Immunizations } \\
\text { (x) }\end{array}$ \\
\hline & & & & $\begin{array}{l}\text { enhance HLA- } \\
\text { A2 binding) }\end{array}$ & & & & & \\
\hline Dijkgraaf & 2015 & $1 / I 1$ & Long peptide & $\begin{array}{l}10 \text { long } \\
\text { peptides } \\
\text { covering WT } \\
\text { p53 (70-248) }\end{array}$ & Ovarian cancer & 8 & $\begin{array}{l}\text { Platinum- } \\
\text { resistant disease }\end{array}$ & Chemotherapy & 2 \\
\hline Hardwick & 2018 & I & $\begin{array}{l}\text { Recombinant } \\
\text { vaccinia Ankara } \\
\text { virus }\end{array}$ & WT FL p53 & Ovarian cancer & 12 & $\begin{array}{l}\text { Platinum- } \\
\text { resistant disease }\end{array}$ & Chemotherapy & 3 \\
\hline Soliman & 2018 & $1 / 11$ & $\begin{array}{l}\text { Recombinant } \\
\text { adenovirus- } \\
\text { transduced DC }\end{array}$ & WT FL p53 & $\begin{array}{l}\text { Breast, colon, gastric, lung, } \\
\text { tongue, ovarian, } \\
\text { chondrosarcoma cancer }\end{array}$ & 194 & $\begin{array}{l}\text { Metastatic } \\
\text { disease }\end{array}$ & Chemotherapy & 4 \\
\hline Chiappori & 2019 & $\|$ & $\begin{array}{l}\text { Recombinant } \\
\text { adenovirus- } \\
\text { transduced DC }\end{array}$ & WT FL p53 & Small cell lung cancer & 78 & $\begin{array}{l}\text { Recurrent } \\
\text { disease }\end{array}$ & Chemotherapy & 3 \\
\hline Chung & 2019 & 1 & $\begin{array}{l}\text { Recombinant } \\
\text { vaccinia Ankara } \\
\text { virus }\end{array}$ & WT FL p53 & $\begin{array}{l}\text { Breast, pancreatic, } \\
\text { hepatocellular, or head and } \\
\text { neck cancer }\end{array}$ & 11 & $\begin{array}{l}\text { Recurrent } \\
\text { disease }\end{array}$ & Chemotherapy & 3 \\
\hline
\end{tabular}

${ }^{a} W T$, wild-type.

${ }^{b} F L$, full-length

peptides by APCs. $\mathrm{p} 53_{264-272}$ or $\mathrm{p} 53_{149-157}$ tetramer ${ }^{+} \mathrm{CD} 8^{+} \mathrm{CTL}$ have been detected in the circulation of head and neck squamous cell carcinomas (HNSCC) patients and negatively correlated with p53 expression in tumor tissues and tumor stage (Albers et al., 2018). These reports suggest that p53-specific CD8 ${ }^{+}$CTLs could eliminate tumor cells, as the immune system has the ability to recognize the $\mathrm{p} 53$ epitopes represented on the surface of cancer cells and APCs. Based on this evidence, a growing number of clinical trials targeting p53 have been conducted (Vermeij et al., 2011; DeLeo and Appella, 2020). This work comprehensively reviews these clinical trials with therapeutic vaccines against $\mathrm{p} 53$. Table 1 contains the clinical trial enrollment information such as vaccine platform, antigen type, and cancer type, and Table 2 provides the information on induced immune and clinical responses in cancer patients.

\section{Peptide Vaccines}

Lomas et al. conducted a phase I trial with up to four doses of a pool of eight short peptides derived from the complementarity determining regions of human anti-p53 antibodies (Lomas et al., 2004). In this trial, 14 patients with solid tumors were enrolled, and six received all four idiotypic vaccinations. The serum antivaccine antibodies were mainly IgG. One patient had increased titers of anti-p53 antibodies. Two patients showed responses in the thymidine proliferation assay to immunized peptides. In contrast to the proliferation assays, no patients had vaccinespecific, IFN- $\gamma$-secreting T cells as assessed by the enzyme-linked immune absorbent spot (ELISpot) assay (Lomas et al., 2004).

Leffers et al. conducted a phase II trial with a p53 synthetic long peptide (p53-SLP) vaccine in 20 ovarian cancer patients (Leffers et al., 2009). The p53-SLP vaccine contains 10 25-30 amino acid long peptides covering WT p53 from position 70-248. Before immunization, eight of 20 patients had p53 autoantibodies associated with p53 expression in primary tumors.
After immunization, nine presented p53-autoantibodies. Before immunization, responses against peptides included in the vaccine were present in three patients. After completing the immunization scheme, all patients had detected vaccineinduced IFN- $\gamma$ producing p53-specific T-cells. These p53specific IFN- $\gamma$ T cells were $\mathrm{CD} 4{ }^{+} \mathrm{CD} 8^{-}$. Two of the total 20 patients had stable disease as evaluated by CA-125 and computerized tomography (CT) and they had vaccine-induced p53-specific responses. Eighteen of 20 patients had clinical, biochemical, and/or radiographic evidence of progressive disease (Leffers et al., 2009). The authors concluded that the p53-SLP vaccine does not affect responses to secondary chemotherapy or survival and that p53-specific $\mathrm{T}$ cells do survive chemotherapy (Leffers et al., 2012).

The p53-SLP vaccine combined with cyclophosphamide therapy is evaluated by Vermeij et al. for treating patients with recurrent ovarian cancer in a single-arm phase II study (Vermeij et al., 2012). Twelve patients were administered four doses of the p53-SLP vaccine at a 3 week interval. Two days before each immunization, patients were treated with cyclophosphamide infusion. After four immunizations, seven of eight evaluable patients displayed vaccine-induced IFN- $\gamma$-producing $\mathrm{p} 53$ specific $\mathrm{T}$ cells, and five produced both T-helper 1 and T-helper-2 cytokines. The p53-SLP vaccine and cyclophosphamide combination therapy had no effect on $\mathrm{T}_{\text {reg }}$ cells. Two patients had stable disease as evaluated by serum CA125 measurement and CT scan, and vaccine-induced p53-specific responses were present in both patients (Vermeij et al., 2012).

Speetjens et al. conducted a phase I/II trial with two doses of the p53-SLP vaccine in 10 metastatic colorectal cancer patients (Speetjens et al., 2009). Six of nine vaccinated patients with p53SLP had p53-specific immune response detected by IFN- $\gamma$ ELISpot. Furthermore, two showed detectable p53 specific $\mathrm{CD}^{+} \mathrm{CD}^{+} \mathrm{CD}_{137^{+}}$cell responses, none had 
TABLE 2 | Immune and clinical response p53-targeting vaccines.

\begin{tabular}{|c|c|c|c|c|c|c|c|c|c|c|}
\hline Author & Year & $\begin{array}{c}\text { Humoral } \\
\text { response }^{a}\end{array}$ & ELISpot & $\begin{array}{l}\text { CD137 } \\
\text { assay }\end{array}$ & $\begin{array}{l}\text { p53-specific } \\
\text { proliferation }^{\text {b }}\end{array}$ & $\begin{array}{c}\text { Treg } \\
\text { frequency } \\
\text { decrease }\end{array}$ & $\begin{array}{c}\text { MDSC } \\
\text { frequency } \\
\text { decrease }\end{array}$ & Immunohistochemistry $^{c}$ & $\begin{array}{c}\text { Clinical } \\
\text { response }^{\mathrm{d}, \mathrm{e}}\end{array}$ & $\begin{array}{c}\text { Adverse } \\
\text { events } \\
\text { (Grade) }\end{array}$ \\
\hline Kuball & 2002 & $0 / 6$ & $0 / 6$ & $\begin{array}{l}\text { Not } \\
\text { analyzed }\end{array}$ & Not analyzed & $\begin{array}{l}\text { Not } \\
\text { analyzed }\end{array}$ & $\begin{array}{l}\text { Not } \\
\text { analyzed }\end{array}$ & 3/6 positive & $\begin{array}{l}\text { 4/6 SD, 2/ } \\
6 \mathrm{PD}\end{array}$ & 1 \\
\hline Menon & 2003 & $\begin{array}{l}\text { Pre } 7 / 15 \\
\text { post } 10 / 15\end{array}$ & $\begin{array}{l}\text { Not } \\
\text { analyzed }\end{array}$ & $\begin{array}{l}\text { Not } \\
\text { analyzed }\end{array}$ & Not analyzed & $\begin{array}{l}\text { Not } \\
\text { analyzed }\end{array}$ & $\begin{array}{l}\text { Not } \\
\text { analyzed }\end{array}$ & Not analyzed & $\begin{array}{l}\text { 1/16 SD, 15/ } \\
16 \text { PD }\end{array}$ & $1 / 2$ \\
\hline Svane & 2004 & $\begin{array}{l}\text { Not } \\
\text { analyzed }\end{array}$ & 4/6 PR & $\begin{array}{l}\text { Not } \\
\text { analyzed }\end{array}$ & Not analyzed & $\begin{array}{l}\text { Not } \\
\text { analyzed }\end{array}$ & $\begin{array}{l}\text { Not } \\
\text { analyzed }\end{array}$ & 3/6 positive & $\begin{array}{l}\text { 2/6 SD, 2/6 } \\
\text { PD, 2/6 } \\
\text { MR/UR }\end{array}$ & $1 / 2$ \\
\hline Lomas & 2004 & $\begin{array}{l}\text { Pre } 0 / 6 \\
\text { post } 1 / 6\end{array}$ & 0/6 PR & $\begin{array}{l}\text { Not } \\
\text { analyzed }\end{array}$ & 2/6 VIR & $\begin{array}{l}\text { Not } \\
\text { analyzed }\end{array}$ & $\begin{array}{l}\text { Not } \\
\text { analyzed }\end{array}$ & 14/14 positive & Not analyzed & $1 / 2$ \\
\hline Antonia & 2006 & $\begin{array}{l}\text { Pre } 10 / 22 \\
\text { post } 10 / 22\end{array}$ & 16/28 PR & $\begin{array}{l}\text { Not } \\
\text { analyzed }\end{array}$ & Not analyzed & No & $\begin{array}{l}\text { Not } \\
\text { analyzed }\end{array}$ & Not analyzed & $\begin{array}{l}\text { 1/29 PR, 7/29 } \\
\text { SD, 21/29 PD }\end{array}$ & $1 / 2$ \\
\hline Herrin & 2007 & $\begin{array}{l}\text { Not } \\
\text { analyzed }\end{array}$ & 14/20 PR & $\begin{array}{l}\text { Not } \\
\text { analyzed }\end{array}$ & Not analyzed & $\begin{array}{l}\text { Not } \\
\text { analyzed }\end{array}$ & $\begin{array}{l}\text { Not } \\
\text { analyzed }\end{array}$ & Not analyzed & Not analyzed & $1-4$ \\
\hline Svane & 2007 & $\begin{array}{l}\text { Not } \\
\text { analyzed }\end{array}$ & 8/22 PR & $\begin{array}{l}\text { Not } \\
\text { analyzed }\end{array}$ & Not analyzed & $\begin{array}{l}\text { Not } \\
\text { analyzed }\end{array}$ & $\begin{array}{l}\text { Not } \\
\text { analyzed }\end{array}$ & 11/26 positive & $\begin{array}{l}\text { 8/19 SD, 11/ } \\
19 \text { PD }\end{array}$ & $1 / 2$ \\
\hline Leffers & 2009 & $\begin{array}{l}\text { Pre } 8 / 20 \\
\text { post } 9 / 20\end{array}$ & 18/18 PR & $\begin{array}{l}\text { Not } \\
\text { analyzed }\end{array}$ & 14/17 PR & $\begin{array}{l}\text { Not } \\
\text { analyzed }\end{array}$ & $\begin{array}{l}\text { Not } \\
\text { analyzed }\end{array}$ & 9/20 positive & $2 \mathrm{SD}, 18 \mathrm{PD}$ & $1 / 2$ \\
\hline Speetjens & 2009 & $\begin{array}{l}\text { Not } \\
\text { analyzed }\end{array}$ & 6/9 PR & $\begin{array}{l}2 / 10 \\
C D 4^{+} \mathrm{PR} \\
0 / 10 \\
\mathrm{CD} 8^{+} \mathrm{PR}\end{array}$ & 7/10 VIR & No & $\begin{array}{l}\text { Not } \\
\text { analyzed }\end{array}$ & 7/10 positive & $\begin{array}{l}\text { 5/10 NED, 5/ } \\
10 \mathrm{RD}\end{array}$ & $1 / 2$ \\
\hline Yoo & 2009 & $\begin{array}{l}\text { Not } \\
\text { analyzed }\end{array}$ & $\begin{array}{l}\text { Not } \\
\text { analyzed }\end{array}$ & $\begin{array}{l}\text { Not } \\
\text { analyzed }\end{array}$ & Not analyzed & $\begin{array}{l}\text { Not } \\
\text { analyzed }\end{array}$ & $\begin{array}{l}\text { Not } \\
\text { analyzed }\end{array}$ & Not analyzed & 3/13 RD & $1-4$ \\
\hline Trepiakas & 2010 & $\begin{array}{l}\text { Not } \\
\text { analyzed }\end{array}$ & 1/4 PR & $\begin{array}{l}\text { Not } \\
\text { analyzed }\end{array}$ & Not analyzed & No & $\begin{array}{l}\text { Not } \\
\text { analyzed }\end{array}$ & Not analyzed & $11 / 36$ SD & $1 / 2$ \\
\hline Rahma & 2012 & $\begin{array}{l}\text { Not } \\
\text { analyzed }\end{array}$ & 14/20 PR & $\begin{array}{l}\text { Not } \\
\text { analyzed }\end{array}$ & Not analyzed & No & $\begin{array}{l}\text { Not } \\
\text { analyzed }\end{array}$ & Not analyzed & $\begin{array}{l}\text { 4/20 NED, 16/ } \\
20 \text { RD }\end{array}$ & $1-4$ \\
\hline Vermeij & 2012 & $\begin{array}{l}\text { Not } \\
\text { analyzed }\end{array}$ & 7/8 PR & $\begin{array}{l}\text { Not } \\
\text { analyzed }\end{array}$ & 5/8 VIR & No & $\begin{array}{l}\text { Not } \\
\text { analyzed }\end{array}$ & 5/12 positive & $\begin{array}{l}2 / 10 \mathrm{SD}, 8 / \\
10 \mathrm{PD}\end{array}$ & $1 / 2$ \\
\hline Iclozan & 2013 & $\begin{array}{l}\text { Not } \\
\text { analyzed }\end{array}$ & $\begin{array}{l}\text { 3/15 PR, 5/ } \\
12 \mathrm{PR}\end{array}$ & $\begin{array}{l}\text { Not } \\
\text { analyzed }\end{array}$ & Not analyzed & No & No & Not analyzed & Not analyzed & $\begin{array}{c}\text { Not } \\
\text { reported }\end{array}$ \\
\hline Zeestraten & 2013 & $\begin{array}{l}\text { Pre } 7 / 8 \\
\text { post } 7 / 8\end{array}$ & 11/11 PR & $\begin{array}{l}\text { Not } \\
\text { analyzed }\end{array}$ & 4/9 VIR & $\begin{array}{l}\text { Not } \\
\text { analyzed }\end{array}$ & $\begin{array}{l}\text { Not } \\
\text { analyzed }\end{array}$ & 8/11 positive & Not analyzed & $1 / 2$ \\
\hline Hardwick & 2014 & $\begin{array}{l}\text { Pre } 0 / 5 \\
\text { post } 5 / 5\end{array}$ & 6/6 PR & $\begin{array}{l}8 / 12 \\
\mathrm{CD} 4^{+} \mathrm{PR}, \\
10 / 12 \\
\mathrm{CD} 8^{+} \mathrm{PR}\end{array}$ & Not analyzed & No & $5 / 9$ & Not analyzed & Not analyzed & $1 / 2$ \\
\hline Schuler & 2014 & $\begin{array}{l}\text { Not } \\
\text { analyzed }\end{array}$ & $\begin{array}{l}\text { 4/16 PR, } \\
\text { 11/16 PR } \\
\text { (Tetramers) }\end{array}$ & $\begin{array}{l}\text { Not } \\
\text { analyzed }\end{array}$ & Not analyzed & $12 / 15$ & $\begin{array}{l}\text { Not } \\
\text { analyzed }\end{array}$ & 8/16 positive & 13/16 NED & $1 / 2$ \\
\hline Dijkgraaf & 2015 & $\begin{array}{l}\text { Not } \\
\text { analyzed }\end{array}$ & 8/8 PR & $\begin{array}{l}\text { Not } \\
\text { analyzed }\end{array}$ & O/8 VIR & No & No & Not analyzed & $\begin{array}{l}\text { 3/6 PD, 1/6 } \\
\mathrm{SD}, 2 / 6 \mathrm{PR}\end{array}$ & $1-4$ \\
\hline Hardwick & 2018 & $\begin{array}{l}\text { Not } \\
\text { analyzed }\end{array}$ & $\begin{array}{l}\text { Not } \\
\text { analyzed }\end{array}$ & $\begin{array}{l}\text { 5/11 } \\
\mathrm{CD} 4^{+} \mathrm{PR} \\
6 / 11 \\
\mathrm{CD} 8^{+} \mathrm{PR}\end{array}$ & Not analyzed & $7 / 11$ & $6 / 11$ & Not analyzed & $\begin{array}{l}\text { 3/11 SD, 1/ } \\
6 \mathrm{PR}\end{array}$ & $1-4$ \\
\hline Soliman & 2018 & $\begin{array}{l}\text { Not } \\
\text { analyzed }\end{array}$ & 7/23 PR & $\begin{array}{l}\text { Not } \\
\text { analyzed }\end{array}$ & Not analyzed & $\begin{array}{l}\text { Not } \\
\text { analyzed }\end{array}$ & $\begin{array}{l}\text { Not } \\
\text { analyzed }\end{array}$ & 44/94 positive & 4/39 SD & $1-5$ \\
\hline Chiappori & 2019 & $\begin{array}{l}\text { Not } \\
\text { analyzed }\end{array}$ & 13/38 PR & $\begin{array}{l}\text { Not } \\
\text { analyzed }\end{array}$ & Not analyzed & $\begin{array}{l}\text { Not } \\
\text { analyzed }\end{array}$ & $\begin{array}{l}\text { Not } \\
\text { analyzed }\end{array}$ & Not analyzed & $\begin{array}{l}\text { 2/61 NED, 13/ } \\
61 \mathrm{SD}, 1 / 61 \\
\mathrm{PR}, 35 / 61 \mathrm{PD}\end{array}$ & $1-3$ \\
\hline Chung & 2019 & $\begin{array}{l}\text { Not } \\
\text { analyzed }\end{array}$ & $\begin{array}{l}\text { Not } \\
\text { analyzed }\end{array}$ & $\begin{array}{l}2 / 11 \\
\mathrm{CD} 4^{+} \mathrm{PR}, \\
2 / 11 \\
\mathrm{CD} 8^{+} \mathrm{PR}\end{array}$ & Not analyzed & $\begin{array}{l}\text { Not } \\
\text { analyzed }\end{array}$ & $\begin{array}{l}\text { Not } \\
\text { analyzed }\end{array}$ & Not analyzed & $\begin{array}{l}3 / 11 \mathrm{SD}, 6 / \\
11 \mathrm{RD}\end{array}$ & $1-4$ \\
\hline
\end{tabular}

${ }^{a}$ Pre- and post-immunization levels of anti-p53-specific antibodies.

${ }^{b}$ p53-specific T-lymphocytes induced by immunizations. PR, positive response; VIR, vaccine-induced response.

${ }^{c} p 53$-staining of primary tumor samples.

${ }^{d} S D$, stable disease; $P D$, progressive disease; MR, mixed response, UR, unconfirmed regression; $P R$, partial response; RD, recurrent disease; NED, no evidence of disease.

${ }^{e}$ All according to Response Evaluation Criteria in Solid Tumors. 
$\mathrm{CD}^{+} \mathrm{CD}^{+} \mathrm{CD} 137^{+}$cell responses. One patient showed a $\mathrm{p} 53$ specific proliferative response before vaccination; seven of 10 patients displayed vaccine-induced p53-specific reactivity after vaccination. Vaccination has no effects on the induction of $\mathrm{p} 53$ specific $\mathrm{T}_{\text {reg }}$ cells. After vaccination, five had no evidence of disease, five showed recurrent disease (Speetjens et al., 2009).

In an ensuing phase I/II clinical trial, the combination of interferon IFN- $\alpha$ and p53-SLP was evaluated in 11 colorectal cancer patients (Zeestraten et al., 2013). The patients were treated with metastasectomy, chemotherapy, and/or radiofrequency ablation (RFA) for disease metastasis. p53-specific IgG antibody responses were detected in seven of eight patients who had serum samples from pre- and post-vaccination. In all patients, p53-SLP vaccination combined with IFN-a treatmentinduced $\mathrm{p} 53$-specific $\mathrm{T}$-cell responses. The toxicity of the combination was limited to Grade 1 or 2 . After the two vaccinations, four of nine patients showed vaccine-induced proliferative responses (Zeestraten et al., 2013).

A phase I/II trial combining gemcitabine, IFN- $\alpha$ and the p53SLP vaccine was conducted in patients with platinum-resistant ovarian cancer by Dijkgraaf et al. (2015). Patients were sequentially treated in three groups: the first three patients received gemcitabine alone, the following six patients received gemcitabine and IFN- $\alpha$ and the remaining six received gemcitabine, IFN- $\alpha$, and additionally p53 SLP vaccine. Patients who received gemcitabine/IFN- $\alpha /$ p53 SLP treatment showed profound T-cell activation and increases in activated T-cell/ $\mathrm{T}_{\text {reg }}$ cell ratios. All p53 SLP vaccinated patients showed detectable p53-specific T-cell responses (Dijkgraaf et al., 2015). Eleven Grade 3/4 adverse events were observed, most likely due to chemotherapy and/or IFN-a (Dijkgraaf et al., 2015).

From the above studies, we can conclude that the p53-SLP vaccine is safe and capable to induce $\mathrm{p} 53$-specific $\mathrm{T}$-cell responses in patients treated for multiple cancers, yet improved survival is yet to come. Most studies are underpowered to demonstrate efficacy in the specific cancer population.

\section{Recombinant Viral Vaccines}

Recombinant viral vaccines aim to use a live virus or attenuated virus to induce an immune response against the viral-encoded antigen (Nascimento and Leite, 2012). There are a number of viral platforms in vaccinations for many pathogens that have thwarted efforts towards control using conventional vaccine approaches (Ewer et al., 2016; Nasar et al., 2017), many of which are used to target p53 in cancer.

In a pilot clinical trial, six advanced-stage cancer patients were immunized with four doses of $\mathrm{rAd} /$ hup53 particles (Kuball et al., 2002). rAd/hup53 is a recombinant replication-defective adenoviral vector encoding human full-length WT p53, and it is capable of priming A2.1-restricted and hup53 epitope-specific CTLs in vivo but unable to induce p53-specific antibodies. After vaccinations, adenoviral backbone induced $\mathrm{CD} 4^{+} \mathrm{T}$ cells and $\mathrm{CD}^{+} \mathrm{T}$ cells in six and two patients, respectively. The treatment was well tolerated, yet no evidence for objective tumor responses was observed (Kuball et al., 2002).

The canarypox virus (ALVAC) is a well-characterized viral vector capable of infecting without replicating in mammalian cells. A phase I/II study was performed on 16 colorectal cancer patients with three intravenously injections of increasing dose of ALVAC encoding the human WT p53 gene (ALVAC-p53) at 3 week intervals (Menon et al., 2003). All patients had metastatic disease of p53-overexpressing colorectal cancer. Fever was the only vaccination-related adverse event. Before the vaccination, seven patients had IgG responses against p53; after vaccination, IgG responses against p53 were induced in three more patients (Menon et al., 2003). Following vaccinations, only one patient showed stable disease, while others showed progressive disease (Menon et al., 2003). No anaphylactic reaction or unwanted autoimmune reactions were observed (Menon et al., 2003).

Modified vaccinia virus Ankara (MVA) is a highly attenuated cytopathic strain replication-competent virus, a well-established vaccinia virus that the Food and Drug Administration has approved as a smallpox vaccine. In a phase I trial of p53MVA (an MVA virus carrying the WT p53 gene), 12 patients with refractory pancreatic and colon cancer were treated with three increasing doses of p53MVA every 3 weeks (Hardwick et al., 2014). Activation-induced CD137 expression is a common marker for antigen-triggered $\mathrm{T}$ cell responses. In this study, four patients had $\mathrm{CD} 137^{+} \mathrm{CD} 4^{+} \mathrm{T}$ cells, and 10 had $\mathrm{CD} 137^{+} \mathrm{CD}^{+} \mathrm{T}$ cells upon stimulation with the $\mathrm{p} 53$ peptide library. An MVA antibody neutralization assay showed that all patients had a low anti-MVA response before vaccination, whereas vaccination increased $\mathrm{T}$ cell reactivity and neutralizing activity against MVA. Patients with lower frequencies of $\mathrm{PD}^{+}$ $\mathrm{CD}^{+} \mathrm{T}$ cells had greater p53-reactive $\mathrm{CD}^{+} \mathrm{T}$ cells after immunization, and antibody blockade of $\mathrm{PD}-1$ in vitro increased the p53 immune responses (Hardwick et al., 2014). This first-in-human single-agent trial showed the p53MVA vaccine is well tolerated and immunogenic, but it showed no significant clinical responses.

Hardwick et al. conducted a dose de-escalating phase I trial of p53MVA vaccine in combination with the gemcitabine chemotherapy (Hardwick et al., 2018). Twelve patients with platinum-resistant ovarian cancer were enrolled in this trial and treated with gemcitabine before three p53MVA vaccinations. Five patients had $\mathrm{CD} 137^{+} \mathrm{CD} 4^{+} \mathrm{T}$ cells, and six had $\mathrm{CD}_{137^{+}} \mathrm{CD}^{+} \mathrm{T}$ cells after vaccination. In 11 patients evaluated for toxicity of the p53MVA/gemcitabine combination therapy, clinical outcome, and immunologic response, none had complete responses, three had stable disease, and one had a partial response on the second posttherapy CT scan (Hardwick et al., 2018).

Chung et al. conducted a phase I trial with the combination of p53MVA and pembrolizumab (anti-PD-1) to treat patients with advanced solid tumors (Chung et al., 2019). Eleven patients with advanced breast, pancreatic, hepatocellular, or head and neck cancer received up to three dose vaccines combined with pembrolizumab at a 3-week interval. They observed clinical responses in three patients who maintained stable disease for up to 49 weeks. Two of them showed increased p53 specific $\mathrm{CD} 137^{+} \mathrm{CD}^{+}$and $\mathrm{CD}^{+} 37^{+} \mathrm{CD}^{+} \mathrm{T}$ cells and upregulated multiple immune response genes (Chung et al., 2019).

Advexin (INGN 201, Ad5CMV-p53) is a replication-impaired adenoviral vector that carries the p53 gene under the 
cytomegalovirus (CMV) promoter and is a well-tolerated and efficacious treatment, both as a monotherapy and in combination with radiation and/or chemotherapy agents (Zhang et al., 1994). Yoo et al. conducted a phase II trial of surgery with perioperative INGN 201 gene therapy. Thirteen patients with advanced, resectable squamous cell carcinoma of the oral cavity and oropharynx were treated with INGN 201 along with surgery and chemoradiotherapy. After surgery, all patients received perioperative INGN 201 injections in the primary tumor bed and the ipsilateral neck. In addition, three patients received injections in the contralateral neck. All but three patients received chemoradiotherapy (Yoo et al., 2009). Of the 10 patients with evaluable data, two experienced Grade 4 adverse events and three died with observed relapses before death (Yoo et al., 2009). Overall, the estimate of 1 year progression-free survival was $92 \%$, yet no definitive conclusion can be made with this small sample size.

\section{DCs Pulsed With p53 Peptides}

Schuler et al. conducted a randomized phase I trial with p53 peptide-pulsed DCs in patients with HNSCC (Schuler et al., 2014). Both class I and class II peptides from p53 are used in this study: p53-sequences 149-157 with T150L and 264-272 with F270W are HLA-A2.1+ restricted (p53-I), and p53-sequence 110-124 are DR4+ restricted (p53-II). A T-helper [Th] tetanus toxoid peptide (Tt-II) is used as a control for p53-II. 16 HLA-A2.1 ${ }^{+}$patients were randomized into three arms: six in arm 1 (DCs with p53-I peptides), four in arm 2 (DCs with p53-I peptides + Tt-II peptide), and six in arm 3 (DCs with p53-I peptides + p53-II peptide). Vaccine-pulsed DCs were delivered to inguinal lymph nodes at the third time point. After vaccination, 12 of 15 patients showed decreased $\mathrm{T}_{\text {reg }}$ cells, and 13 had no evidence of disease in a median follow-up of 32 months. Eight patients had p53-positive tumors, but there was no difference in disease-free survival between patients with p53positive versus p53-negative tumors (Schuler et al., 2014). There were no Grade $2-4$ adverse events.

Svane et al. conducted a phase I trial of vaccination with p53 peptide-pulsed DCs in patients with advanced breast cancer (Svane et al., 2004). Six HLA-A2-associated p53 short peptides were used ( $3 \mathrm{WT}$ and three were mutated to enhance HLA-A2 binding), along with and a pan-MHC class II peptide, PADRE. Nine patients received 10 immunizations with p53- and PADREpeptide-pulsed autologous DCs. Before vaccination, two of them had T-cell reactivity against p53 peptides. After four or six vaccinations, four patients showed increased specific T-cell responses against p53 peptides. In three patients with vaccineinduced reactivity, $\mathrm{T}$-cell responses were declined at late time intervals. Two patients maintained stable disease for more than 6 months (Svane et al., 2004).

A phase II trial of vaccination with the same p53 peptidepulsed DCs for patients with advanced breast cancer was conducted by Svane et al. (2007). This phase II trial enrolled 26 patients with progressive metastatic breast cancer patients. Eight of 22 evaluated patients had p53-specific CTLs after immunization. p53 was frequently expressed in tumors from patients achieving stable disease. Five of six patients with stable disease expressed p53, whereas only six of 18 with progressive disease. Overall, among 19 patients available for first evaluation after six vaccinations, eight had stable disease, and 11 had progressive disease, supporting an effect of p53-specific vaccination (Svane et al., 2007).

Trepiakas et al. conducted a phase I/II trial with DCs pulsed with multiple tumor peptides from $\mathrm{p} 53$, survivin, and telomerase in 46 patients with malignant melanoma (Trepiakas et al., 2010). The p53 peptides (and the PADRE peptide) were the same as above. One out of four patients had increased lysate-specific IFN$\gamma$ response as detected by ELISpot, and six of 10 showed detectable antigen-specific T cell response as assessed by MHC multimer assays. After six vaccinations, compared to patients with progressive disease, patients with stable disease displayed significantly lower $\mathrm{T}_{\text {reg }}$ cells. Thirty-six patients had a clinical response: 11 had stable disease, six had continued stable disease after 16 weeks, and six had continued stable disease after 19 weeks (Trepiakas et al., 2010).

In an ensuing phase II study, metastatic melanoma patients were treated with p53 peptides-pulsed DC vaccination with interleukin-2, metronomic cyclophosphamide, and a Cox-2 inhibitor. The same six p53 peptides and the PADRE peptide were used. Among 28 patients evaluated: 16 had stable disease, and 12 had progressive disease (Ellebaek et al., 2012). The authors concluded that DC vaccination in combination with IL-2, cyclophosphamide, and the Cox-2 inhibitor was safe and tolerable, and a general increase in immune responses was observed upon fourth vaccination; however, a correlation between clinical benefit and a vaccine-induced $\mathrm{T}$-cell response could not be determined (Ellebaek et al., 2012).

Herrin et al. conducted a randomized phase II trial with p53 vaccine to compare subcutaneous direct administration with intravenous peptide-pulsed DCs in high-risk ovarian cancer patients (Herrin et al., 2007). A single WT p53 epitope (264-272) with high HLA-A2.1 affinity was used for vaccination. Twenty-one patients were enrolled in this phase II study. On the subcutaneous arm, nine of 13 patients had an immunologic response. On the intravenous arm, five of seven had an immunologic response. Mean overall survival on the subcutaneous and intravenous arm is 70.4 and 72.9 months, respectively (Herrin et al., 2007).

\section{DCs Transduced With Virus}

Antonia et al. tested a cancer vaccine based on adenovirustransduced DCs (Ad.p53-DC) in a phase I/II study (Antonia et al., 2006). The virus expressed a full-length WT human p53. Twenty-nine patients with late-stage small cell lung cancer (SCLC) enrolled and received three vaccinations every 2 weeks. Ten patients had a detectable level of anti-p53 antibody before vaccination, and only three had a significantly increased anti-p53 antibodies level after immunization. p53-specific T cell responses were detected in 13 of 25 patients who underwent the IFN- $\gamma$ ELISpot assay (Antonia et al., 2006). Among evaluated patients treated with this vaccine, one achieved a partial response, seven showed stable disease, and 21 developed progressive disease (Antonia et al., 2006). 
Forkhead box protein P3 (FOXP3) expressing regulatory $\mathrm{T}$ $\left(\mathrm{T}_{\text {reg }}\right)$ cells are a subset of $\mathrm{CD}^{+} \mathrm{T}$ cells with high immunosuppressive activity, which is critical cells for maintaining dominant self-tolerance and immune homeostasis (Togashi et al., 2019). $\mathrm{T}_{\text {reg }}$ cells exert their immunosuppressive activity through various cellular and humoral mechanisms, including cytotoxic $\mathrm{T}$ lymphocyte antigen 4 (CTLA-4)mediated suppression of APCs, consumption of IL-2, and production of immune inhibitory cytokines and molecules (Spolski et al., 2018; Tekguc et al., 2021). $\mathrm{T}_{\text {reg }}$ cells can suppress anti-tumor immunity, and $\mathrm{T}_{\text {reg }}$ cells dysregulation is associated with a poor prognosis in human cancer patients (Wang and Ke, 2011; Saito et al., 2016). There are two types of antigens presented in tumor cells, including non-self-antigens, also known as neoantigens, derived from either oncogenic viral proteins or mutant proteins, and self-antigens, which are generated from highly or aberrantly expressed endogenous proteins. Self-antigens reactive $\mathrm{CD}^{+} \mathrm{T}$ cells exhibit an anergic phenotype owing to suppression by $\mathrm{T}_{\text {reg }}$ cells, while non-selfspecific $\mathrm{CD}^{+} \mathrm{T}$ cells showed resistance to $\mathrm{T}_{\text {reg }}$ cells mediated suppression in humans (Maeda et al., 2014). Thus, $\mathrm{T}_{\text {reg }}$ cells exert more effective suppression in immune responses against selfantigens than non-self-antigens. Programmed cell death 1 (PD-1) is a negative regulator of $\mathrm{T}_{\text {reg }}$ cells as well as effector $\mathrm{T}$ cells, suggesting that $\mathrm{PD}-1$ blockade enhances the suppressive function of $\mathrm{T}_{\text {reg }}$ cells (Kamada et al., 2019; Kumagai et al., 2020). The effects of $\mathrm{p} 53$-targeting vaccination on $\mathrm{T}_{\text {reg }}$ cells were estimated in this Ad.p53-DC phase I/II study (Antonia et al., 2006). Before or after vaccination, there was no significant change of these cells in healthy subjects and patients with SCLC, and no statistically significant link between the presence of these cells in the patients' blood and p53-specific T cell responses (Antonia et al., 2006).

Myeloid-derived suppressor cells (MDSCs) are a heterogeneous population of cells. MDSCs are pathologically activated myeloid progenitors and immature myeloid cells with potent immunosuppressive activity (Hegde et al., 2021; Veglia et al., 2021). A number of studies have demonstrated that MDSCs are implicated in T cell suppression and are closely associated with poor clinical outcomes in cancer (Wang et al., 2020b; Imazeki et al., 2021). Mouse experiment also demonstrated that MDSC depletion with antibodies or different compounds could substantially improve anti-tumor immune responses to exert anti-tumor effects (Gabrilovich et al., 2012). Iclozan et al. conducted a randomized phase II trial in patients with late-stage SCLC using the Ad.p53-DC vaccine (Iclozan et al., 2013). Fifty-six patients were randomized into one of three arms: 18 to arm A (control), 19 to arm B (the Ad.p53-DC vaccine alone), and 19 to arm C (the Ad. p53-DC vaccine plus all-trans retinoic acid (ATRA). ATRA substantially decreases MDSC. Patients were administrated with the Ad.p53-DC vaccine three times at 2 week intervals. The Ad.p53-DC vaccine alone showed no effect on the frequency of MDSC and $\mathrm{T}_{\text {reg, }}$, while the $\mathrm{p} 53$ vaccine combined with ATRA significantly decreased MDSCs (Iclozan et al., 2013). In addition, three patients in arm B had p53-specific immune response, and five in arm $\mathrm{C}$ had detectable p53 response (Iclozan et al., 2013). In a following article, Chiappori reported the clinical results of a randomized-controlled phase II trial of patients with recurrent SCLC with the same three arms (Chiappori et al., 2019). No immune response was detected in arm A (control), three of 15 patients showed positive immune responses in arm B, and 10 had positive immune response in arm $\mathrm{C}$. In arm $\mathrm{B}$, two patients maintained complete response, four had stable disease, 13 had progressive disease, and one had partial response. In arm $\mathrm{C}$, nine patients had stable disease and 22 had progressive disease (Chiappori et al., 2019).

A phase-I/II study of the Ad. p53-DC vaccine in combination with indoximod in metastatic tumors were reported by Soliman et al. (2018). Forty-four patients with p53-positive by immunohistochemistry were enrolled in this trial. Seven of 23 patients had increased $\mathrm{CD}^{+} \mathrm{T}$ cell positive response, and six showed increased $\mathrm{CD}^{+} \mathrm{CD}^{2} 9^{+} \mathrm{T}$ cells at week 3. During the vaccination period, no objective responses occurred; stable disease was observed in four patients at week 7 (Soliman et al., 2018). Overall, the Ad.p53-DC vaccine is safe and elicits immune responses, yet it fails to improve the overall response to chemotherapy.

\section{CONCLUSION}

p53 is mutated in about half of all cancers and has attracted great interest in the development of cancer vaccines. An increasing number of studies on $\mathrm{p} 53$ vaccines, either peptide-, virus-, or DCbased for cancer immunotherapy, have been reported. Several vaccines have been tested in multiple clinical trials: p53-SLP, p53MVA, DCs with six p53 peptides and the PADRE peptide, and DCs transduced with Ad.p53. Key findings from these published clinical trials are summarized (Tables 1, 2). First, the p53 vaccines themselves are safe, albeit patients may have high-grade adverse events when they have adjunctive chemotherapy. Second, p53 vaccines elicit p53-specific immune responses. Third, current p53 vaccines do not improve patient survival to justify even a phase III trial, let alone approved to treat patients. Finally, current p53 vaccines are largely dependent on WT p53 full-length protein or peptides, which may circumvent the avidity of the CTLs due to self-tolerance (Theobald et al., 1997; Kuball et al., 2002). As vaccination technologies have unprecedented progress and successes during the COVID-19 pandemic, we call for further development of personalized p53-targeting vaccines with the following provocative questions. 1) Should we include antibodies in assays testing the $\mathrm{B}$ cell responses in addition to $\mathrm{T}$ cell activation? Mutant p53 is known to be released into the circulation of cancer patients (Sobhani et al., 2020). It is unclear whether the elicited antibodies from vaccines targeting mutant p53 in the serum or within the tumors offer therapeutic benefits. At a minimum, these antibodies may attract APCs to the tumor sites where mutant p53 antigens enrich. 2) Should we worry about autoimmune reactions targeting the endogenous WT p53 in physiologic tissues? Current p53 vaccines do not show widespread anaphylactic and autoimmune toxicities. It is notable that the $\mathrm{R} 175 \mathrm{H}$ neoantigen is only presented $1.3-2.4$ copies per cell in several tumor cell lines carrying the $\mathrm{R} 175 \mathrm{H}$ 
mutation (Hsiue et al., 2021). It is unlikely that low endogenous WT p53 within normal tissues pose a serious challenge for $\mathrm{T}$ cell autoimmune response. 3) Will improved delivery methods help? mRNAs encapsulated in lipid nanoparticles (LNP) elicit about 5fold neutralizing antibodies against the antigen (Spike) compared to adenoviral vectors (Khoury et al., 2021). mRNA-LNP may deliver mutant p53 better than outdated delivery approaches. 4) Will enhanced immunogenicity of p53 help? Structural changes in p53, via either stabilizing mutants (Boeckler et al., 2008) or adding self-assembling modules (He et al., 2021), could maximize the host's p53 expression, presentation, and immunogenicity. 5) Shall we construct one vaccine for one p53 mutant? Each amino acid substitution in p53 may alter the p53 conformation differently (Wang and Fersht, 2015; Joerger and Fersht, 2016), so the final degradation products from one $\mathrm{p} 53$ mutant may differ considerably from another mutant or the WT p53 that is rarely overexpressed in cancer. The human $\mathrm{T}$ cell repertoire is not necessarily devoid of low- and even residual high-avidity p53specific CTLs, yet self-tolerance certainly limits the number of high-avidity CTLs binding to MHC-restricted WT p53 peptides (Theobald et al., 1997; Kuball et al., 2002). Rational design of next-generation personalized p53 vaccines requires an in-depth understanding of mutant $\mathrm{p} 53$ structure and function, proteolysis,

\section{REFERENCES}

Albers, A. E., Qian, X., Kaufmann, A. M., Mytilineos, D., Ferris, R. L., Hoffmann, T. K., et al. (2018). Phenotype of P53 Wild-Type Epitope-Specific T Cells in the Circulation of Patients With Head and Neck Cancer. Sci. Rep. 8, 10716. doi:10.1038/s41598-018-29067-5

Antonia, S. J., Mirza, N., Fricke, I., Chiappori, A., Thompson, P., Williams, N., et al. (2006). Combination of P53 Cancer Vaccine With Chemotherapy in Patients With Extensive Stage Small Cell Lung Cancer. Clin. Cancer Res. 12, 878-887. doi:10.1158/1078-0432.ccr-05-2013

Boeckler, F. M., Joerger, A. C., Jaggi, G., Rutherford, T. J., Veprintsev, D. B., and Fersht, A. R. (2008). Targeted Rescue of a Destabilized Mutant of P53 by an In Silico Screened Drug. Proc. Natl. Acad. Sci. 105, 10360-10365. doi:10.1073/ pnas. 0805326105

Boettcher, S., Miller, P. G., Sharma, R., McConkey, M., Leventhal, M., Krivtsov, A. V., et al. (2019). A Dominant-Negative Effect Drives Selection of TP53 Missense Mutations in Myeloid Malignancies. Science 365, 599-604. doi:10.1126/ science.aax3649

Bouaoun, L., Sonkin, D., Ardin, M., Hollstein, M., Byrnes, G., Zavadil, J., et al. (2016). TP53Variations in Human Cancers: New Lessons from the IARC TP53 Database and Genomics Data. Hum. Mutat. 37, 865-876. doi:10.1002/ humu. 23035

Boutelle, A. M., and Attardi, L. D. (2021). p53 and Tumor Suppression: It Takes a Network. Trends Cell Biol. 31, 298-310. doi:10.1016/j.tcb.2020.12.011

Brady, C. A., Jiang, D., Mello, S. S., Johnson, T. M., Jarvis, L. A., Kozak, M. M., et al. (2011). Distinct P53 Transcriptional Programs Dictate Acute DNA-Damage Responses and Tumor Suppression. Cell 145, 571-583. doi:10.1016/ j.cell.2011.03.035

Chen, S., Wu, J.-L., Liang, Y., Tang, Y.-G., Song, H.-X., Wu, L.-L., et al. (2021). Arsenic Trioxide Rescues Structural P53 Mutations Through a Cryptic Allosteric Site. Cancer Cell. 39, 225-239.e8. doi:10.1016/j.ccell.2020.11.013

Chiappori, A. A., Williams, C. C., Gray, J. E., Tanvetyanon, T., Haura, E. B., Creelan, B. C., et al. (2019). Randomized-Controlled Phase II Trial of Salvage Chemotherapy after Immunization With a TP53-Transfected Dendritic CellBased Vaccine (Ad.p53-DC) in Patients With Recurrent Small Cell Lung Cancer. Cancer Immunol. Immunother. 68, 517-527. doi:10.1007/s00262018-2287-9
$\mathrm{B}$ and $\mathrm{T}$ cell elicitation, vaccine trafficking and retention, antigen expression and presentation, germinal center reactions, and selftolerance. Such knowledge is essential to achieve the most effective precision vaccine candidates to be tested in clinical trials, in order to reduce cancer mortality from p53 mutation.

\section{AUTHOR CONTRIBUTIONS}

SZ contributed to drafting the manuscript; CF, ZZ, and $\mathrm{KY}$ contributed to concept discussion and manuscript revision; YL contributed to the design and editing of the manuscript.

\section{FUNDING}

This work is support by grants from National Institutes of Health (CA219556 and CA229080). YL is a CPRIT Scholar in Cancer Research supported by the Cancer Prevention and Research Institute of Texas (RR190043) and is supported in part by the Superfund Hazardous Substance Research and Training Program from National Institutes of Health (P42 ES027725).

Chikamatsu, K., Albers, A., Stanson, J., Kwok, W. W., Appella, E., Whiteside, T. L., et al. (2003). P53(110-124)-Specific Human CD4+ T-Helper Cells Enhance In Vitro Generation and Antitumor Function of Tumor-Reactive CD8+ T Cells. Cancer Res. 63, 3675-3681.

Chikamatsu, K., Nakano, K., Storkus, W. J., Appella, E., Lotze, M. T., Whiteside, T. L., et al. (1999). Generation of Anti-p53 Cytotoxic T Lymphocytes From Human Peripheral Blood Using Autologous Dendritic Cells. Clin. Cancer Res. 5, 1281-1288.

Chung, V., Kos, F. J., Hardwick, N., Yuan, Y., Chao, J., Li, D., et al. (2019). Evaluation of Safety and Efficacy of p53MVA Vaccine Combined With Pembrolizumab in Patients With Advanced Solid Cancers. Clin. Transl Oncol. 21, 363-372. doi:10.1007/s12094-018-1932-2

DeLeo, A. B., and Appella, E. (2020). The P53 Saga: Early Steps in the Development of Tumor Immunotherapy. J. Immunol. 204, 2321-2328. doi:10.4049/ jimmunol.1901343

Dijkgraaf, E. M., Santegoets, S. J. A. M., Reyners, A. K. L., Goedemans, R., Nijman, H. W., van Poelgeest, M. I. E., et al. (2015). A Phase 1/2 Study Combining Gemcitabine, Pegintron and P53 SLP Vaccine in Patients With PlatinumResistant Ovarian Cancer. Oncotarget 6, 32228-32243. doi:10.18632/ oncotarget.4772

Ellebaek, E., Engell-Noerregaard, L., Iversen, T. Z., Froesig, T. M., Munir, S., Hadrup, S. R., et al. (2012). Metastatic Melanoma Patients Treated With Dendritic Cell Vaccination, Interleukin-2 and Metronomic Cyclophosphamide: Results From a Phase II Trial. Cancer Immunol. Immunother. 61, 1791-1804. doi:10.1007/s00262-012-1242-4

Ewer, K. J., Lambe, T., Rollier, C. S., Spencer, A. J., Hill, A. V., and Dorrell, L. (2016). Viral Vectors as Vaccine Platforms: From Immunogenicity to Impact. Curr. Opin. Immunol. 41, 47-54. doi:10.1016/j.coi.2016.05.014

Gabrilovich, D. I., Ostrand-Rosenberg, S., and Bronte, V. (2012). Coordinated Regulation of Myeloid Cells by Tumours. Nat. Rev. Immunol. Immunol. 12, 253-268. doi:10.1038/nri3175

Hardwick, N. R., Carroll, M., Kaltcheva, T., Qian, D., Lim, D., Leong, L., et al (2014). p53MVA Therapy in Patients with Refractory Gastrointestinal Malignancies Elevates P53-Specific CD8+ T-Cell Responses. Clin. Cancer Res. 20, 4459-4470. doi:10.1158/1078-0432.ccr-13-3361

Hardwick, N. R., Frankel, P., Ruel, C., Kilpatrick, J., Tsai, W., Kos, F., et al. (2018). p53-Reactive T Cells are Associated With Clinical Benefit in Patients With Platinum-Resistant Epithelial Ovarian Cancer After Treatment With a P53 
Vaccine and Gemcitabine Chemotherapy. Clin. Cancer Res. 24, 1315-1325. doi:10.1158/1078-0432.ccr-17-2709

He, L., Lin, X., Wang, Y., Abraham, C., Sou, C., Ngo, T., et al. (2021). SingleComponent, Self-Assembling, Protein Nanoparticles Presenting the Receptor Binding Domain and Stabilized Spike as SARS-CoV-2 Vaccine Candidates. Sci. $A d v$. 7, eabf1591. doi:10.1126/sciadv.abf1591

Hegde, S., Leader, A. M., and Merad, M. (2021). MDSC: Markers, Development, States, and Unaddressed Complexity. Immunity 54, 875-884. doi:10.1016/ j.immuni.2021.04.004

Hernández Borrero, L. J., and El-Deiry, W. S. (2021). Tumor Suppressor P53: Biology, Signaling Pathways, and Therapeutic Targeting. Biochim. Biophys. Acta Rev. Cancer 1876, 188556. doi:10.1016/j.bbcan.2021.188556

Herrin, V. E., Achtar, M. S., Steinberg, S. M., Whiteside, T. L., Wieckowski, E., Czystowska, M., et al. (2007). A Randomized Phase II P53 Vaccine Trial Comparing Subcutaneous Direct Administration With Intravenous PeptidePulsed Dendritic Cells in High Risk Ovarian Cancer Patients. J. Clin. Oncol. 25, 3011. doi:10.1200/jco.2007.25.18_suppl.3011

Hollstein, M., Sidransky, D., Vogelstein, B., and Harris, C. (1991). p53 Mutations in Human Cancers. Science 253, 49-53. doi:10.1126/science.1905840

Hossain, M. A., Liu, G., Dai, B., Si, Y., Yang, Q., Wazir, J., et al. (2021). Reinvigorating Exhausted CD8 + Cytotoxic T Lymphocytes in the Tumor Microenvironment and Current Strategies in Cancer Immunotherapy. Med. Res. Rev. 41, 156-201. doi:10.1002/med.21727

Houbiers, J. G. A., Nijman, H. W., van der Burg, S. H., Drijfhout, J. W., Kenemans, P., van de Velde, C. J. H., et al. (1993). In Vitro induction of Human Cytotoxic T Lymphocyte Responses Against Peptides of Mutant and Wild-Type P53. Eur. J. Immunol. 23, 2072-2077. doi:10.1002/eji.1830230905

Hsiue, E. H., Wright, K. M., Douglass, J., Hwang, M. S., Mog, B. J., Pearlman, A. H., et al. (2021). Targeting a Neoantigen Derived From a Common TP53 Mutation. Science 371, eabc8697. doi:10.1126/science.abc8697

Huang, J. (2021). Current Developments of Targeting the P53 Signaling Pathway for Cancer Treatment. Pharmacol. Ther. 220, 107720. doi:10.1016/ j.pharmthera.2020.107720

Iclozan, C., Antonia, S., Chiappori, A., Chen, D.-T., and Gabrilovich, D. (2013). Therapeutic Regulation of Myeloid-Derived Suppressor Cells and Immune Response to Cancer Vaccine in Patients With Extensive Stage Small Cell Lung Cancer. Cancer Immunol. Immunother. 62, 909-918. doi:10.1007/s00262-013$1396-8$

Imazeki, H., Ogiwara, Y., Kawamura, M., Boku, N., and Kudo-Saito, C. (2021). CD11b(+)CTLA4(+) Myeloid Cells Are a Key Driver of Tumor Evasion in Colorectal Cancer. J. Immunother. Cancer 9, e002841. doi:10.1136/jitc-2021002841

Ito, D., Albers, A., Zhao, Y. X., Visus, C., Appella, E., Whiteside, T. L., et al. (2006). The Wild-type Sequence (Wt) P53(25-35) Peptide Induces HLA-DR7 and HLA-DR11-Restricted CD4+ Th Cells Capable of Enhancing the Ex Vivo Expansion and Function of Anti-wt P53(264-272) Peptide CD8+ T Cells. J. Immunol. 177 (10), 6795-6803. doi:10.4049/jimmunol.177.10.6795

Iwakuma, T., and Lozano, G. (2007). Crippling P53 Activities via Knock-In Mutations in Mouse Models. Oncogene 26, 2177-2184. doi:10.1038/ sj.onc. 1210278

Janic, A., Valente, L. J., Wakefield, M. J., Di Stefano, L., Milla, L., Wilcox, S., et al. (2018). DNA Repair Processes Are Critical Mediators of P53Dependent Tumor Suppression. Nat. Med. 24, 947-953. doi:10.1038/ s41591-018-0043-5

Joerger, A. C., and Fersht, A. R. (2007). Structural Biology of the Tumor Suppressor P53 and Cancer-Associated Mutants. Adv. Cancer Res. 97, 1-23. doi:10.1016/ s0065-230x(06)97001-8

Joerger, A. C., and Fersht, A. R. (2016). The P53 Pathway: Origins, Inactivation in Cancer, and Emerging Therapeutic Approaches. Annu. Rev. Biochem. 85, 375-404. doi:10.1146/annurev-biochem-060815-014710

Kamada, T., Togashi, Y., Tay, C., Ha, D., Sasaki, A., Nakamura, Y., et al. (2019). PD-1+ Regulatory $\mathrm{T}$ Cells Amplified by PD-1 Blockade Promote Hyperprogression of Cancer. Proc. Natl. Acad. Sci. USA. 116, 9999-10008. doi:10.1073/pnas.1822001116

Kandoth, C., McLellan, M. D., Vandin, F., Ye, K., Niu, B., Lu, C., et al. (2013). Mutational Landscape and Significance Across 12 Major Cancer Types. Nature. 502, 333-339. doi:10.1038/nature12634
Karni-Schmidt, O., Lokshin, M., and Prives, C. (2016). The Roles of MDM2 and MDMX in Cancer. Annu. Rev. Pathol. Mech. Dis. 11, 617-644. doi:10.1146/ annurev-pathol-012414-040349

Keshelava, N., Zuo, J. J., Chen, P., Waidyaratne, S. N., Luna, M. C., Gomer, C. J., et al. (2001). Loss of P53 Function Confers High-Level Multidrug Resistance in Neuroblastoma Cell Lines. Cancer Res. 61, 6185-6193.

Khoury, D. S., Cromer, D., Reynaldi, A., Schlub, T. E., Wheatley, A. K., Juno, J. A., et al. (2021). Neutralizing Antibody Levels are Highly Predictive of Immune Protection from Symptomatic SARS-CoV-2 Infection. Nat. Med. 27, 1205-1211. doi:10.1038/s41591-021-01377-8

Kuball, J., Schuler, M., Antunes Ferreira, E., Herr, W., Neumann, M., ObenauerKutner, L., et al. (2002). Generating P53-Specific Cytotoxic T Lymphocytes by Recombinant Adenoviral Vector-Based Vaccination in Mice, but Not Man. Gene Ther. 9, 833-843. doi:10.1038/sj.gt.3301709

Kumagai, S., Togashi, Y., Kamada, T., Sugiyama, E., Nishinakamura, H., Takeuchi, Y., et al. (2020). The PD-1 Expression Balance Between Effector and Regulatory T Cells Predicts the Clinical Efficacy of PD-1 Blockade Therapies. Nat. Immunol. 21, 1346-1358. doi:10.1038/s41590-020-0769-3

Leffers, N., Lambeck, A. J. A., Gooden, M. J. M., Hoogeboom, B. N., Wolf, R., Hamming, I. E., et al. (2009). Immunization With a P53 Synthetic Long Peptide Vaccine Induces P53-specific Immune Responses in Ovarian Cancer Patients, a Phase II Trial. Int. J. Cancer 125, 2104-2113. doi:10.1002/ijc.24597

Leffers, N., Vermeij, R., Hoogeboom, B.-N., Schulze, U. R., Wolf, R., Hamming, I. E., et al. (2012). Long-Term Clinical and Immunological Effects of P53-SLP Vaccine in Patients With Ovarian Cancer. Int. J. Cancer 130, 105-112. doi:10.1002/ijc.25980

Leroy, B., Anderson, M., and Soussi, T. (2014). TP53 Mutations in Human Cancer: Database Reassessment and Prospects for the Next Decade. Hum. Mutat. 35, 672-688. doi:10.1002/humu.22552

Li, T., Kon, N., Jiang, L., Tan, M., Ludwig, T., Zhao, Y., et al. (2012). Tumor Suppression in the Absence of P53-Mediated Cell-Cycle Arrest, Apoptosis, and Senescence. Cell 149, 1269-1283. doi:10.1016/j.cell.2012.04.026

Liu, Y., Leslie, P. L., and Zhang, Y. (2021). Life and Death Decision-Making by P53 and Implications for Cancer Immunotherapy. Trends Cancer 7, 226-239. doi:10.1016/j.trecan.2020.10.005

Lomas, M., Liauw, W., Packham, D., Williams, K., Kelleher, A., Zaunders, J., et al. (2004). Phase I Clinical Trial of a Human Idiotypic P53 Vaccine in Patients With Advanced Malignancy. Ann. Oncol. 15, 324-329. doi:10.1093/annonc/ mdh053

Lujambio, A., Akkari, L., Simon, J., Grace, D., Tschaharganeh, D. F., Bolden, J. E., et al. (2013). Non-Cell-autonomous Tumor Suppression by P53. Cell 153, 449-460. doi:10.1016/j.cell.2013.03.020

Maeda, Y., Nishikawa, H., Sugiyama, D., Ha, D., Hamaguchi, M., Saito, T., et al. (2014). Detection of Self-Reactive CD8 + T Cells With an Anergic Phenotype in Healthy Individuals. Science 346, 1536-1540. doi:10.1126/science.aaa1292

Malkin, D., Li, F. P., Strong, L. C., Fraumeni, J. F., Jr., Nelson, C. E., Kim, D. H., et al. (1990). Germ Line P53 Mutations in a Familial Syndrome of Breast Cancer, Sarcomas, and Other Neoplasms. Science 250, 1233-1238. doi:10.1126/ science. 1978757

Manfredi, J. J. (2021). Mdm2 and MdmX: Partners in P53 Destruction. Cancer Res. 81, 1633-1634. doi:10.1158/0008-5472.can-21-0145

Mantovani, F., Collavin, L., and Del Sal, G. (2019). Mutant P53 as a Guardian of the Cancer Cell. Cell Death Differ. 26, 199-212. doi:10.1038/s41418-018-0246-9

Marciscano, A. E., and Anandasabapathy, N. (2021). The Role of Dendritic Cells in Cancer and Anti-tumor Immunity. Semin. Immunol. 52, 101481. doi:10.1016/ j.smim.2021.101481

Mcllwrath, A. J., Vasey, P. A., Ross, G. M., and Brown, R. (1994). Cell Cycle Arrests and Radiosensitivity of Human Tumor Cell Lines: Dependence on Wild-Type P53 for Radiosensitivity. Cancer Res. 54, 3718-3722.

Menon, A. G., Kuppen, P. J. K., van der Burg, S. H., Offringa, R., Bonnet, M. C., Harinck, B. I. J., et al. (2003). Safety of Intravenous Administration of a Canarypox Virus Encoding the Human Wild-Type P53 Gene in Colorectal Cancer Patients. Cancer Gene Ther. 10, 509-517. doi:10.1038/sj.cgt.7700600

Nakayama, M., Hong, C. P., Oshima, H., Sakai, E., Kim, S.-J., and Oshima, M. (2020). Loss of Wild-Type P53 Promotes Mutant P53-Driven Metastasis Through Acquisition of Survival and Tumor-Initiating Properties. Nat. Commun. 11, 2333. doi:10.1038/s41467-020-16245-1 
Nasar, F., Matassov, D., Seymour, R. L., Latham, T., Gorchakov, R. V., Nowak, R. M., et al. (2017). Recombinant Isfahan Virus and Vesicular Stomatitis Virus Vaccine Vectors Provide Durable, Multivalent, Single-Dose Protection against Lethal Alphavirus Challenge. J. Virol. 91, e01729. doi:10.1128/JVI.01729-16

Nascimento, I. P., and Leite, L. C. C. (2012). Recombinant Vaccines and the Development of New Vaccine Strategies. Braz. J. Med. Biol. Res. 45, 1102-1111. doi:10.1590/s0100-879x2012007500142

Noguchi, Y., Chen, Y. T., and Old, L. J. (1994). A Mouse Mutant P53 Product Recognized by CD4+ and CD8+ T Cells. Proc. Natl. Acad. Sci. 91, 3171-3175. doi:10.1073/pnas.91.8.3171

Petitjean, A., Achatz, M. I. W., Borresen-Dale, A. L., Hainaut, P., and Olivier, M. (2007). TP53 Mutations in Human Cancers: Functional Selection and Impact on Cancer Prognosis and Outcomes. Oncogene 26, 2157-2165. doi:10.1038/ sj.onc. 1210302

Ramqvist, T., Magnusson, K. P., Wang, Y., Szekely, L., Klein, G., and Wiman, K. G. (1993). Wild-Type P53 Induces Apoptosis in a Burkitt Lymphoma (BL) Line that Carries Mutant P53. Oncogene. 8, 1495-1500.

Rojas, J. M., McArdle, S. E. B., Horton, R. B. V., Bell, M., Mian, S., Li, G., et al. (2005). Peptide Immunisation of HLA-DR?transgenic Mice Permits the Identification of a Novel HLA-DR? $1^{*} 0101$ ? and HLA-DR? $1^{*} 0401$ ? restricted Epitope from P53. Cancer Immunol. Immunother. 54, 243-253. doi:10.1007/ s00262-004-0596-7

Saito, T., Nishikawa, H., Wada, H., Nagano, Y., Sugiyama, D., Atarashi, K., et al. (2016). Two FOXP3+CD4+ T Cell Subpopulations Distinctly Control the Prognosis of Colorectal Cancers. Nat. Med. 22, 679-684. doi: $10.1038 / \mathrm{nm} .4086$

Salomao, N., Karakostis, K., Hupp, T., Vollrath, F., Vojtesek, B., and Fahraeus, R. (2021). What Do We Need to Know and Understand About P53 to Improve its Clinical Value? J. Pathol. 254, 443. doi:10.1002/path.5677

Schuler, P. J., Harasymczuk, M., Visus, C., Deleo, A., Trivedi, S., Lei, Y., et al. (2014). Phase I Dendritic Cell P53 Peptide Vaccine for Head and Neck Cancer. Clin. Cancer Res. 20, 2433-2444. doi:10.1158/1078-0432.ccr-13-2617

Sharma, M. D., Rodriguez, P. C., Koehn, B. H., Baban, B., Cui, Y., Guo, G., et al. (2018). Activation of P53 in Immature Myeloid Precursor Cells Controls Differentiation into Ly6c+CD103+ Monocytic Antigen-Presenting Cells in Tumors. Immunity. 48, 91-106. doi:10.1016/j.immuni.2017.12.014

Sobhani, N., D’Angelo, A., Wang, X., Young, K. H., Generali, D., and Li, Y. (2020). Mutant P53 as an Antigen in Cancer Immunotherapy. Int. J. Mol. Sci. 21, 4087. doi:10.3390/ijms21114087

Soliman, H., Khambati, F., Han, H. S., Ismail-Khan, R., Bui, M. M., Sullivan, D. M., et al. (2018). A Phase-1/2 Study of Adenovirus-P53 Transduced Dendritic Cell Vaccine in Combination With Indoximod in Metastatic Solid Tumors and Invasive Breast Cancer. Oncotarget 9, 10110-10117. doi:10.18632/ oncotarget. 24118

Speetjens, F. M., Kuppen, P. J. K., Welters, M. J. P., Essahsah, F., Voet van den Brink, A. M. E. G., Lantrua, M. G. K., et al. (2009). Induction of P53-Specific Immunity by a P53 Synthetic Long Peptide Vaccine in Patients Treated for Metastatic Colorectal Cancer. Clin. Cancer Res. 15, 1086-1095. doi:10.1158/ 1078-0432.ccr-08-2227

Spolski, R., Li, P., and Leonard, W. J. (2018). Biology and Regulation of IL-2: From Molecular Mechanisms to Human Therapy. Nat. Rev. Immunol. 18, 648-659. doi:10.1038/s41577-018-0046-y

Steinman, R. M., Adams, J. C., and Cohn, Z. A. (1975). Identification of a Novel Cell Type in Peripheral Lymphoid Organs of Mice. IV. Identification and Distribution in Mouse Spleen. J. Exp. Med. 141, 804-820. doi:10.1084/ jem.141.4.804

Steinman, R. M., and Cohn, Z. A. (1973). Identification of a Novel Cell Type in Peripheral Lymphoid Organs of Mice. J. Exp. Med. 137, 1142-1162. doi:10.1084/jem.137.5.1142

Steinman, R. M., and Cohn, Z. A. (1974). Identification of a Novel Cell Type in Peripheral Lymphoid Organs of Mice. J. Exp. Med. 139, 380-397. doi:10.1084/ jem.139.2.380

Svane, I. M., Pedersen, A. E., Johansen, J. S., Johnsen, H. E., Nielsen, D., Kamby, C., et al. (2007). Vaccination With P53 Peptide-Pulsed Dendritic Cells Is Associated with Disease Stabilization in Patients With P53 Expressing Advanced Breast Cancer; Monitoring of Serum YKL-40 and IL-6 as Response Biomarkers. Cancer Immunol. Immunother. 56, 1485-1499. doi:10.1007/s00262-007-0293-4
Svane, I. M., Pedersen, A. E., Johnsen, H. E., Nielsen, D., Kamby, C., Gaarsdal, E., et al. (2004). Vaccination with P53-Peptide?Pulsed Dendritic Cells, of Patients With Advanced Breast Cancer: Report From a Phase I Study. Cancer Immunol. Immunother. 53, 633-641. doi:10.1007/s00262-003-0493-5

Tang, Q., Su, Z., Gu, W., and Rustgi, A. K. (2020). Mutant P53 on the Path to Metastasis. Trends Cancer 6, 62-73. doi:10.1016/j.trecan.2019.11.004

Tekguc, M., Wing, J. B., Osaki, M., Long, J., and Sakaguchi, S. (2021). TregExpressed CTLA-4 Depletes CD80/CD86 by Trogocytosis, Releasing Free PDL1 on Antigen-Presenting Cells. Proc. Natl. Acad. Sci. USA. 118, e2023739118. doi:10.1073/pnas.2023739118

Theobald, M., Biggs, J., Dittmer, D., Levine, A. J., and Sherman, L. A. (1995). Targeting P53 as a General Tumor Antigen. Proc. Natl. Acad. Sci. USA. 92, 11993-11997. doi:10.1073/pnas.92.26.11993

Theobald, M., Biggs, J., Hernández, J., Lustgarten, J., Labadie, C., and Sherman, L. A. (1997). Tolerance to P53 by A2.1-Restricted Cytotoxic T Lymphocytes. J. Exp. Med. 185, 833-842. doi:10.1084/jem.185.5.833

Togashi, Y., Shitara, K., and Nishikawa, H. (2019). Regulatory T Cells in Cancer Immunosuppression - Implications for Anticancer Therapy. Nat. Rev. Clin. Oncol. 16, 356-371. doi:10.1038/s41571-019-0175-7

Trepiakas, R., Berntsen, A., Hadrup, S. R., Bjørn, J., Geertsen, P. F., Straten, P. T., et al. (2010). Vaccination With Autologous Dendritic Cells Pulsed With Multiple Tumor Antigens for Treatment of Patients With Malignant Melanoma: Results from a Phase I/II Trial. Cytotherapy 12, 721-734. doi:10.3109/14653241003774045

Veglia, F., Sanseviero, E., and Gabrilovich, D. I. (2021). Myeloid-Derived Suppressor Cells in the Era of Increasing Myeloid Cell Diversity. Nat. Rev. Immunol. 21, 485-498. doi:10.1038/s41577-020-00490-y

Vermeij, R., Leffers, N., van der Burg, S. H., Melief, C. J., Daemen, T., and Nijman, H. W. (2011). Immunological and Clinical Effects of Vaccines Targeting P53Overexpressing Malignancies. J. Biomed. Biotechnol. 2011, 702146. doi:10.1155/ 2011/702146

Vermeij, R., Leffers, N., Hoogeboom, B.-N., Hamming, I. L. E., Wolf, R., Reyners, A. K. L., et al. (2012). Potentiation of a P53-SLP Vaccine by Cyclophosphamide in Ovarian Cancer: A Single-Arm Phase II Study. Int. J. Cancer. 131, E670-E680. doi:10.1002/ijc.27388

Wade, M., Wang, Y. V., and Wahl, G. M. (2010). The P53 Orchestra: MDM2 and MDMX Set the Tone. Trends Cell Biology. 20, 299-309. doi:10.1016/ j.tcb.2010.01.009

Wang, G., and Fersht, A. R. (2015). Propagation of Aggregated P53: CrossReaction and Coaggregation vs. Seeding. Proc. Natl. Acad. Sci. USA. 112, 2443-2448. doi:10.1073/pnas.1500262112

Wang, J., and Ke, X.-Y. (2011). The Four Types of Tregs in Malignant Lymphomas. J. Hematol. Oncol. 4, 50. doi:10.1186/1756-8722-4-50

Wang, X., and Sun, Q. (2017). TP53 Mutations, Expression and Interaction Networks in Human Cancers. Oncotarget 8, 624-643. doi:10.18632/ oncotarget. 13483

Wang, Y., Ding, Y., Deng, Y., Zheng, Y., and Wang, S. (2020a). Role of MyeloidDerived Suppressor Cells in the Promotion and Immunotherapy of ColitisAssociated Cancer. J. Immunother. Cancer 8, e000609. doi:10.1136/jitc-2020000609

Wang, Y., Xiang, Y., Xin, V. W., Wang, X.-W., Peng, X.-C., Liu, X.-Q., et al. (2020b). Dendritic Cell Biology and its Role in Tumor Immunotherapy. J. Hematol. Oncol. 13, 107. doi:10.1186/s13045-020-00939-6

Wu, D., and Prives, C. (2018). Relevance of the P53-MDM2 Axis to Aging. Cell Death Differ. 25, 169-179. doi:10.1038/cdd.2017.187

Yang, J., Jin, A., Han, J., Chen, X., Zheng, J., and Zhang, Y. (2021). MDMX Recruits $\mathrm{UbcH5c}$ to Facilitate MDM2 E3 Ligase Activity and Subsequent P53 Degradation In Vivo. Cancer Res. 81, 898-909. doi:10.1158/0008-5472.can20-0790

Yoo, G. H., Moon, J., Leblanc, M., Lonardo, F., Urba, S., Kim, H., et al. (2009). A Phase 2 Trial of Surgery With Perioperative INGN 201 (Ad5CMV-P53) Gene Therapy Followed by Chemoradiotherapy for Advanced, Resectable Squamous Cell Carcinoma of the Oral Cavity, Oropharynx, Hypopharynx, and Larynx. Arch. Otolaryngol. Head Neck Surg. 135, 869-874. doi:10.1001/ archoto.2009.122

Zeestraten, E. C. M., Speetjens, F. M., Welters, M. J. P., Saadatmand, S., Stynenbosch, L. F. M., Jongen, R., et al. (2013). Addition of Interferon- $\alpha$ to the P53-SLP Vaccine Results in Increased Production of Interferon- $\gamma$ in 
Vaccinated Colorectal Cancer Patients: A Phase I/II Clinical Trial. Int. J. Cancer 132, 1581-1591. doi:10.1002/ijc.27819

Zhang, W. W., Fang, X., Mazur, W., French, B. A., Georges, R. N., and Roth, J. A. (1994). High-efficiency Gene Transfer and High-Level Expression of WildType P53 in Human Lung Cancer Cells Mediated by Recombinant Adenovirus. Cancer Gene Ther. 1, 5-13.

Zhou, J., Kryczek, I., Li, S., Li, X., Aguilar, A., Wei, S., et al. (2021). The Ubiquitin Ligase MDM2 Sustains STAT5 Stability to Control T Cell-Mediated Antitumor Immunity. Nat. Immunol. 22, 460-470. doi:10.1038/s41590-021-00888-3

Conflict of Interest: The authors declare that the research was conducted in the absence of any commercial or financial relationships that could be construed as a potential conflict of interest.
Publisher's Note: All claims expressed in this article are solely those of the authors and do not necessarily represent those of their affiliated organizations, or those of the publisher, the editors and the reviewers. Any product that may be evaluated in this article, or claim that may be made by its manufacturer, is not guaranteed or endorsed by the publisher.

Copyright $\odot 2021$ Zhou, Fan, Zeng, Young and Li. This is an open-access article distributed under the terms of the Creative Commons Attribution License (CC BY).

The use, distribution or reproduction in other forums is permitted, provided the original author(s) and the copyright owner(s) are credited and that the original publication in this journal is cited, in accordance with accepted academic practice. No use, distribution or reproduction is permitted which does not comply with these terms. 